\title{
Estudio de genética poblacional de Polylepis pauta y Polylepis sericea en Pichincha mediante la utilización de marcadores moleculares SSRs
}

\author{
Rosa Andrade ${ }^{1}$, Mónica Jadán ${ }^{1}$ y Claudia Segovia-Salcedo ${ }^{1,2}$ \\ ${ }^{1}$ Grupo de Conservación de Bosques de Polylepis. Facultad de Biotecnología, ESPE, \\ Sangolquí, Ecuador roselena2007@hotmail.com \\ ${ }^{2}$ Deparment of Biology. University of Florida. Gainesville, Florida. EEUU \\ claudia@ufl.edu
}

Recibido: 10, 01, 2013; aceptado: 01, 10, 2013

\begin{abstract}
RESUMEN.- Los bosques de Polylepis son centros de biodiversidad con alto impacto antropogénico. En nuestro país no existen estudios de estructura genética en el género, información indispensable para su conservación genética. El presente estudio se centra en dos especies con conflicto taxonómico: P. pauta y P. sericea en la provincia de Pichincha (Yanacocha, Mojanda y Cayambe-Coca). En total se analizaron 142 individuos de las tres poblaciones. El ADN se extrajo mediante el método CTAB para luego amplificarlo con cinco microsatélites diseñados para este género. Se detectaron 18 alelos compartidos entre las dos especies. El análisis mediante Structure reveló la existencia de dos grupos. El primero conformado por Cayambe-Coca y Mojanda y el otro por Yanacocha. Los valores de heterocigocidad observada (Ho) en Cayambe-Coca, Mojanda y Yanacocha fueron de 0.576 y 0.299 . Mientras que la esperada (He) fue de 0.605 y 0.524 . La mayor diferencia corresponde a Yanacocha y se puede atribuir a la selección a favor de un alelo o endogamia. Mediante análisis de diferenciación se comprobó que ambos grupos son diferentes con $\mathrm{p}=0.00072(\alpha=0.05)$. AMOVA mostró que la mayor variación corresponde a dentro de las poblaciones $(88 \%)$. El análisis de agrupamiento detectó dos grupos: el primero conformado por Cayambe-Coca y Mojanda, y el segundo por Yanacocha. Sin embargo, se detectó un agrupamiento diferente para la subpoblación Mojanda 1 ( $P$. pauta $\times$ P. incana). No se encontró correlación entre distancia genética y distancia geográfica. En este estudio se pudo diferenciar a ambas especies molecularmente, por lo cual se demuestra que los SSRs diseñados fueron marcadores poderosos en análisis de diversidad, diferenciación y estructura en este género.
\end{abstract}

PALABRAS CLAVES: conservación, genética poblacional, Polylepis, SSRs 
ABSTRACT.- Polylepis forests are one of the most vulnerable centers of Andean diversity that have been affected by anthropogenic impacts. In Ecuador there are no studies of genetic structure in this genus, which is fundamental information for genetic conservation. This study analyzed two species with taxonomic uncertainty, P. pauta and P. sericea, in three populations: Yanacocha, Mojanda, and Cayambe-Coca National Park. Each population consisted of three subpopulations with a total of 142 individuals. DNA was extracted using the CTAB method and was amplified with 5 SSR primers designed for this genus. Eighteen alleles were detected between the two species. Analysis for genetic structure detected two groups. The first one contained the Cayambe-Coca and Mojanda populations and Yanacocha was in the second group. The observed heterogeneity (Ho) for the Cayambe-Coca and Mojanda population was 0.576, and 0.299 for the Yanacocha population. In contrast, the expected heterogeneity $(\mathrm{He})$ was 0.605 and 0.524 for the populations in Cayambe-Coca and Mojanda and Yanacocha. The biggest difference between these statistics was in the Yanacocha population. This could be attributable to one allele selection or inbreeding. Through differentiation analysis it was probed that both population established are different $\mathrm{p}=0.00072(\alpha=0.05)$. The largest source of variation corresponds to within populations differences (AMOVA). Clustering analysis detected a significant clustering in a subpopulation from Mojanda (Moj1). This may be due to a hybrid origin (P.pauta $\times$ P. incana) of this population. Correlation between genetic and geographic distance was not detected. Through this study it was possible to differentiate both species; therefore, SSRs were powerful markers to detect genetic diversity, differentiation, and population structure in this genus.

KEYWORDS: conservation, Polylepis, population genetics, SSRs

\section{INTRODUCCIÓN}

A nivel mundial durante el período de 1990 al 2012, se han reportado las mayores reducciones de áreas de bosques en los trópicos en países en vías de desarrollo (White et al., 2007). Es más, se estima que más del $98 \%$ del bosque primario en el mundo se ha perdido debido a actividades humanas en los últimos 1000 años. Los Andes no son la excepción, en los cuales los bosques de Polylepis entre los ecosistemas más amenazados en el Neotrópico (Gareca et al., 2013). Se estima que la tasa de deforestación en el Ecuador es del $3 \%$ anual; está dentro de los países con el porcentaje más alto de deforestación en Latinoamérica, con pérdidas entre 60000 a 200000 hectáreas de bosques nativos, que son resultado de cortes ilegales, expansión de los cultivos, presión por compañías mineras y petroleras (Mecham, 2001). 
La fragmentación de estos bosques genera varios cambios, entre ellos la alteración de los patrones de flujo génico, con aumento de la diferenciación entre las poblaciones y por ende una disminución en el éxito reproductivo de los individuos, debido a la endogamia (White et al., 2007; Fjeldsa y Kessler, 1996). En nuestro país se han identificado 7 especies nativas pertenecientes al género Polylepis, entre las cuales se encuentran $P$. weberbaueri, P. pauta, $P$. sericea, $P$. incana, $P$. microphylla, $P$. reticulata y $P$. lanuginosa; las dos últimas son endémicas de nuestro país (Romoleroux y Pitman, 2004). Los bosques de Poylepis proveen numerosos servicios ecológicos que han sido subestimados durante siglos por una falta de conocimiento. Las hojas agrupadas al final de las ramas colectan agua de la neblina típica de los ecosistemas altoandinos. Su fuerte relación con musgos y líquenes ayudan a controlar el flujo del agua. Estos bosques proveen refugio de cientos de plantas y animales muchos de ellos endémicos. A pesar de la importancia de Polylepis, en los ecosistemas altoandinos no existen estudios suficientes sobre la estructura genética de sus especies (Gareca et al., 2013). Con la información obtenida en este estudio será posible elaborar proyectos de restauración y de reforestación exitosos que contribuyan a un manejo adecuado y conservación de los bosques de Polylepis en el Ecuador.
En este trabajo se pretende examinar la estructura genética de $P$. pauta y $P$. sericea, ambas especies con características morfológicas similares (Segovia-Salcedo et al., 2010; Romoleroux, 1996). Mediante este estudio será posible diferenciarlas molecularmente con el propósito de resolver el conflicto taxonómico de las mismas. Este es el primer trabajo realizado en este género con la utilización de los marcadores microsatélites diseñados para este grupo taxonómico, por lo cual los resultados obtenidos son promisorios para investigaciones futuras.

\section{MATERIALES Y MÉTODOS}

Recolección y conservación del material vegetal.- En la presente investigación, se utilizaron hojas frescas recolectadas en las salidas de campo, así como muestras botánicas. Las hojas fueron colectadas en bolsas plásticas e inmediatamente colocadas en neveras portátiles para evitar la oxidación del material. Se recolectaron muestras de tres poblaciones: Cayambe-Coca, Mojanda y Yanacocha, con un total de 142 individuos en la provincia de Pichincha. Cada población constó de tres subpoblaciones, con un promedio de 15.7 individuos por subpoblación. Ejemplares colectados en cada una de las poblaciones se encuentran depositados en el Herbario Nacional (QCNE) (Tabla 1). 


\section{Tabla 1}

Descripción de las muestras de Polylepis pauta y Polylepis sericea recolectados para el presente estudio

\begin{tabular}{|c|c|c|c|}
\hline Población & Especie & Ubicación Geográfica (UTM) y elevación & $\begin{array}{l}\text { Número de } \\
\text { Individuos } \\
\text { Colectados }\end{array}$ \\
\hline CayCoca1 & & $\begin{array}{c}\text { Parque Nacional Cayambe Coca } \\
178190529966764 \\
3980 \mathrm{msnm}\end{array}$ & 12 \\
\hline CayCoca2 & P. pauta-P. sericea & $\begin{array}{c}\text { Parque Nacional Cayambe Coca } \\
178194669975197 \\
3912 \mathrm{msnm}\end{array}$ & 17 \\
\hline СayCoca3 & & $\begin{array}{c}\text { Parque Nacional Cayambe Coca } \\
178187929979339 \\
3700 \mathrm{msnm}\end{array}$ & 12 \\
\hline Yan1 & & $\begin{array}{c}\text { Reserva Privada Yanacocha } \\
177683139986267 \\
3539 \mathrm{mnsm}\end{array}$ & 19 \\
\hline Yan2 & P. sericea & $\begin{array}{c}\text { Reserva Privada Yanacocha } \\
177686979985884 \\
3820 \mathrm{msnm}\end{array}$ & 18 \\
\hline Yan 3 & & $\begin{array}{c}\text { Reserva Privada Yanacocha } \\
177686629985191 \\
3831 \mathrm{msnm}\end{array}$ & 18 \\
\hline Moj1 & P. pauta X P. incana & $\begin{array}{l}\text { Lagunas de Mojanda } \\
1780573215302 \\
3775 \mathrm{msnm}\end{array}$ & 17 \\
\hline Moj2 & P. pauta & $\begin{array}{l}\text { Lagunas de Mojanda } \\
1780430613454 \\
3850 \mathrm{msnm}\end{array}$ & 13 \\
\hline Moj3 & P. pauta & $\begin{array}{l}\text { Lagunas de Mojanda } \\
1780309916624 \\
3722 \mathrm{msnm}\end{array}$ & 16 \\
\hline
\end{tabular}

Los individuos (árboles) en los (GPS), con los cuales se elaboraron mapas muestreos fueron seleccionados al azar, de distribución mediante el programa además se tomó una distancia mínima MapSource 6.13.7 y GPS Visualizer 2012. de $10 \mathrm{~m}$ entre individuos para asegurar Las poblaciones muestreadas corresponden que se estaban recolectando individuos a tres sectores: Cayambe-Coca, Mojanda diferentes. En todas las salidas de campo se y Yanacocha de la provincia de Pichincha georeferenciaron los puntos de colección (Figura 1). 


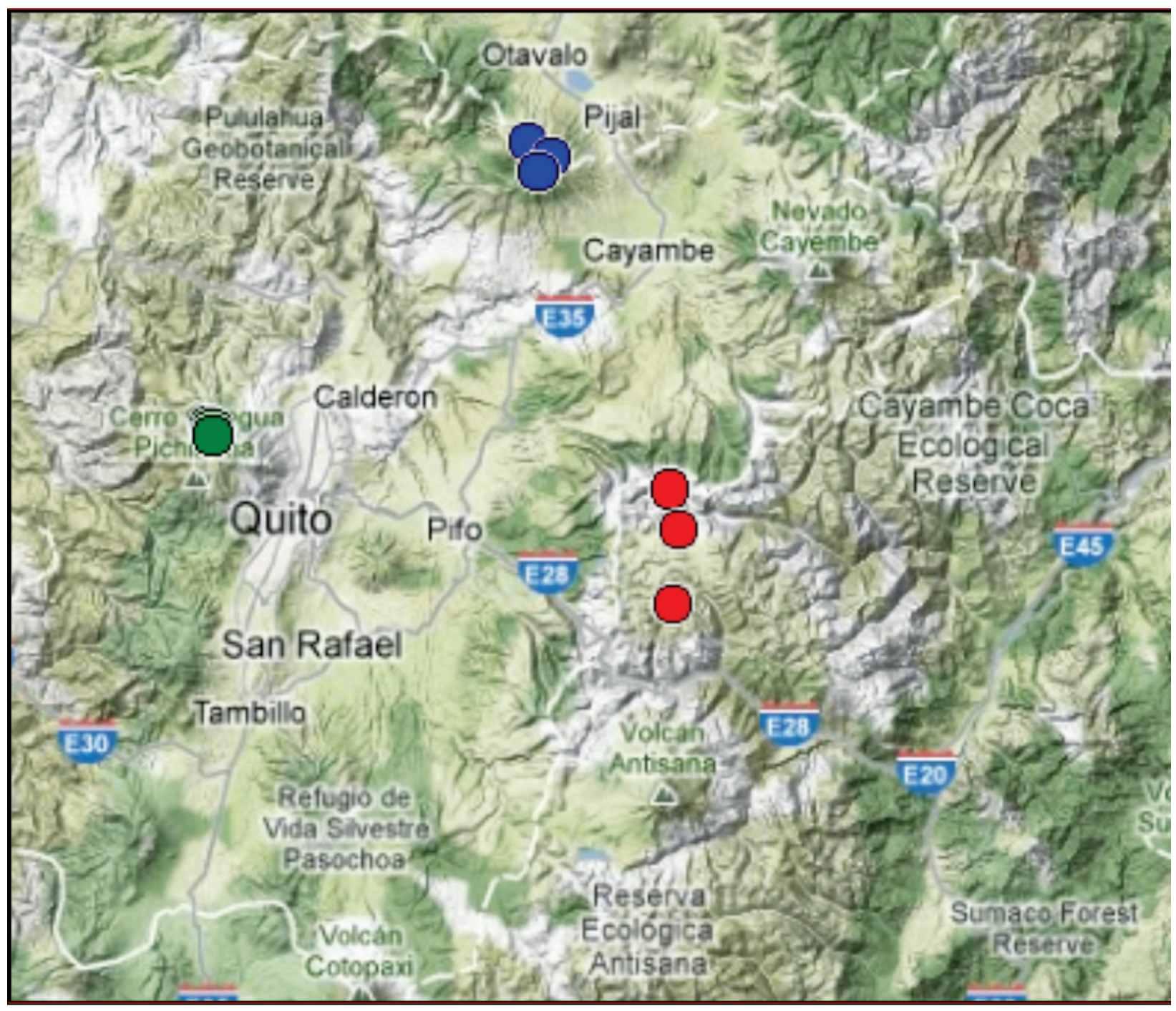

Figura 1. Genética poblacional Polylepis pauta y Polylepis sericea en Pichincha mediante SSRs. Mapa de distribución de las muestras recolectadas de P. pauta y P. sericea. Reserva Cayambe Coca (círculos rojos), Fundación Conservación Jocotoco, Yanacocha (círculos verdes), Mojanda (círculos azules). Mapa elaborado mediante MapSource y GPS Visualizer.

La distancia en línea recta entre las poblaciones de Yanacocha y Mojanda es de $44.4 \mathrm{~km}$, la distancia entre Mojanda y Cayambe-Coca es de $47.9 \mathrm{~km}$ y entre Cayambe-Coca y Yanacocha es de $51 \mathrm{~km}$. Las poblaciones de Yanacocha seencuentran en la cordillera Occidental, mientras que las de Cayambe-Coca y de Mojanda se encuentran en la cordillera Oriental.
Extracción y cuantificación de ADN genómico.- La extracción de ADN genómico en tejidos vegetales implica: remoción de las membranas que cubren el ADN, separación del ADN de otros componentes celulares y el mantenimiento de la integridad del ADN durante el proceso. Para la extracción de $\mathrm{ADN}$ se probaron 4 protocolos: Doyle y Doyle, 
1987; Porebski et al., 1997; Khanuja et al., y calidad en estas muestras de Polylepis se 1999 y un protocolo modificado de CTAB. llevó a cabo mediante el protocolo de CTAB De acuerdo con los resultados obtenidos modificado (Figura 2).

la extracción de ADN con mayor cantidad

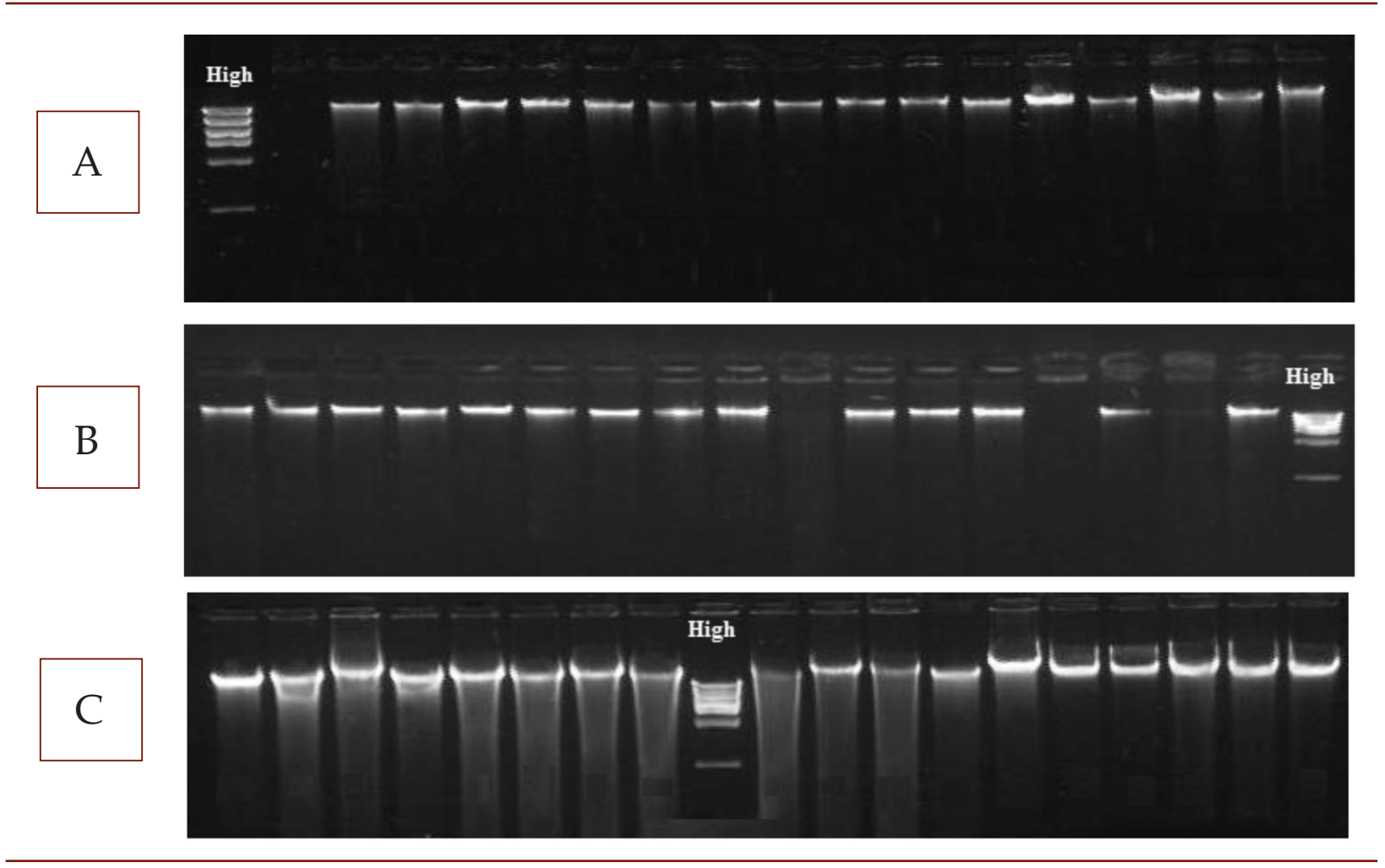

Figura 2. Electroforesis en geles de agarosa al $0.8 \%$ teñido con Sybr Safe $(0.035 \mathrm{ng} / \mathrm{ml}$ de gel $)$ para la verificación de la calidad de ADN de las poblaciones de Polylepis. A) Cayambe Coca, B) Mojanda C) Yanacocha. High: Marcador de alto peso molecular.

Para este protocolo, primero se tampón de extracción. Al momento de congelaron tanto los morteros como los la extracción se añadió en el tampón de pistilos a $-20^{\circ} \mathrm{C}$. Después se colocó en extracción (CTAB $2 \%$, EDTA $0.25 \mathrm{M}, \mathrm{NaCl}$ ellos la muestra (5 g) y se la maceró con $5 \mathrm{M} \mathrm{y} \mathrm{Tris-} \mathrm{HCl} 1 \mathrm{M}(\mathrm{pH} 8)$ los antioxidantes nitrógeno líquido, hasta obtener una (PVP 2\% y $15 \mu 1 \beta$-Mercaptoetanol). En cada muestra pulverizada. Este macerado se microtubo de $2 \mathrm{ml}$ se colocaron $800 \mu \mathrm{l}$ de lo almacenó en tubos Falcon de $15 \mathrm{ml}$ en este tampón y fueron mezclados mediante el congelador de $-80^{\circ} \mathrm{C}$ hasta su posterior pistilos y con vórtex hasta obtener una uso. Para la extracción de ADN se pesaron solución homogénea. Luego, se colocaron aproximadamente $200 \mathrm{mg}$ del macerado $400 \mu \mathrm{l}$ más de tampón hasta que se obtuvo anterior en microtubos de $2 \mathrm{ml}$ y se los una muestra completamente disuelta en el mantuvo en nitrógeno hasta colocar el tampón de extracción. A esta solución se 
la incubó a $65^{\circ} \mathrm{C}$ durante una hora. Una vez enfriados los tubos, se añadieron en la sorbona $800 \mu \mathrm{l}$ de CIA (24:1). Después, se agitó vigorosamente en el vórtex, hasta obtener una emulsión blanquecina. A esta emulsión se la centrifugó a $14500 \mathrm{rpm}$ por 10 minutos. Y se traspasó el sobrenadante a un tubo de $1.5 \mathrm{ml}$ sin topar la interfase presente. Luego, se añadieron $700 \mu \mathrm{l}$ de isopropanol a $-20^{\circ} \mathrm{C}$ y se guardaron los tubos a $-20^{\circ} \mathrm{C}$ durante 2 horas. En caso de no visualizarse el precipitado de ADN se incubó por 1-2 horas más en $-20^{\circ} \mathrm{C}$. Después, se centrifugaron los tubos por 15 minutos a $14500 \mathrm{rpm}$ y el sobrenadante obtenido se lo descartó. Luego, se realizaron dos lavados del precipitado con $300 \mu \mathrm{l}$ de etanol al $70 \%$ a $-20^{\circ} \mathrm{C}$. Una vez realizados estos dos lavados se realizó un lavado final con $200 \mu \mathrm{l}$ de etanol puro. Todos los lavados se los realizó en un termobloque a $300 \mathrm{rpm}$ por 5 minutos, seguido de 3 min de centrifugación rápida. Una vez concluidos los lavados se evaporaron los restos del alcohol presente, de preferencia esto se lo realizó en una sorbona por unos 30 minutos. Después, se resuspendió este pellet, para incubarlo a $37^{\circ} \mathrm{C}$ con $100 \mu \mathrm{l}$ de tampón TE y $3 \mu$ lde RNAasa por una hora o hasta que se observó la completa disolución del mismo. Una vez disuelto el ADN se lo almacenó durante una media hora a $4^{\circ} \mathrm{C}$ y después se realizaron alícuotas a $20 \mathrm{ng} / \mu \mathrm{l}$. Estas alícuotas se almacenaron a $4^{\circ} \mathrm{C}$ y el resto en el congelador de $-80^{\circ} \mathrm{C}$.

La calidad y cantidad de ADN extraído se la evaluó mediante fluorometría con el uso de Quant-iT dsDNA BR Assay,
INVITROGEN $®$ y con geles de agarosa al $0.8 \%$ teñidos con Sybr Safe $(0.035 \mu \mathrm{l} / \mathrm{ml}$ de gel). En la corrida se incluyeron $2 \mu \mathrm{l}$ de un marcador de peso, High DNA Mass Ladder INVITROGEN $\AA$, a un voltaje constante de $120 \mathrm{~V}$ por una hora. La visualización de esta corrida electroforética se la realizó mediante un transiluminador de luz UV, VILBER LOURMAT TFX- 20.M y el almacenamiento se lo realizó en el equipo Bio-DocIT System.

\section{Amplificación de secuencias micro-} satélites.- Los primers específicos para la amplificación de los microsatélites utilizados en este estudio, fueron diseñados en el laboratorio de Sistemática Molecular y Genética Evolutiva de la Universidad de Florida a partir de una biblioteca genómica de $P$. racemosa (datos no publicados). Se analizaron 32 primers para microsatélites. Para la validación de estos primers se procedió primero con una TD-PCR (Touchdown PCR), para verificar la amplificación. Las condiciones de temperatura y de tiempo para la amplificación fueron: 3 minutos a $94^{\circ} \mathrm{C}, 35$ ciclos (30 segundos a $94^{\circ} \mathrm{C}, 45 \mathrm{se}-$ gundos en $\left(46,48,50\right.$ y $\left.52^{\circ} \mathrm{C}\right), 30$ segundos a $72^{\circ} \mathrm{C}$ ), finalmente una extensión de 20 minutos a $72^{\circ} \mathrm{C}$. El volumen de reacción final fue de $10 \mu \mathrm{l}$, mediante concentraciones 1X Tampón, $1.5 \mathrm{mM} \mathrm{MgCl}_{2}, 0.05 \mathrm{mM}$ de dNTPs, $0.45 \mu \mathrm{M}$ de primer Forward, 0,45 $\mu \mathrm{M}$ de primer Reverse, $1.8 \mathrm{U} / \mu 1$ de Taq polimerasa y para completar la reacción $6.24 \mu 1$ de agua PCR.

Se utilizaron cinco sets de primers: 2F-2Ra, 2F-2Rb， 13F-13R，17F-17Ra y 
20F-20R (Tabla 2), que fueron seleccionados por brindar los datos más polimórficos en cada población.
El primer paso fue la búsqueda de controles positivos adecuados en base a los alelos presentes en la población.

\section{Tabla 2}

Sets de Primers empleados con su respectiva secuencia

\begin{tabular}{|c|c|c|}
\hline Primer & Secuencia del primer & $\mathrm{T}$ alineamiento \\
\hline $2 \mathrm{~F}$ & CACGACGTTGTAAAACGACATAGAAGCCCTGACTCTAAC & $50^{\circ} \mathrm{C}$ \\
\hline $2 \mathrm{Ra}$ & TCTGAGACACTGAGGAATAC & \\
\hline $2 \mathrm{~F}$ & CACGACGTTGTAAAACGACATAGAAGCCCTGACTCTAAC & \\
\hline $2 \mathrm{Rb}$ & TGTCATTGCTAAATCACTTC & \\
\hline $13 \mathrm{~F}$ & CACGACGTTGTAAAACGACCTCCATAAATCATGAGACTG & $52^{\circ} \mathrm{C}$ \\
\hline $13 \mathrm{R}$ & TGTCATCGAGACCATTTAC & \\
\hline $17 \mathrm{~F}$ & CACGACGTTGTAAAACGACCTCCATAAATCATGAGACTG & $50^{\circ} \mathrm{C}$ \\
\hline $17 \mathrm{Ra}$ & CGAGACCATTTACATTGC & \\
\hline $20 \mathrm{~F}$ & CACGACGTTGTAAAACGACCTTGGTAGTGAAATTTGAAG & \\
\hline & & $52^{\circ} \mathrm{C}$ \\
\hline 20R & TGGAGTTGTAATGGTATCC & \\
\hline
\end{tabular}

Después con estos controles se realizaron hora. Los geles fueron visualizados bajo luz dupletas de todas las muestras. En UV y se fotodocumentaron para seleccionar todas las validaciones se incluyeron los mejores patrones de los alelos en las controles negativos y el marcador de peso poblaciones de estudio.

molecular Track-It 100 bp DNA Ladder de INVITROGEN ${ }$. Los productos de PCR

Análisis de datos.- Los datos fueron fueron visualizados mediante electroforesis registrados en una matriz de Microsoft en geles de agarosa al $3 \%$ a $100 \mathrm{~V}$ por una Office Excel 2007, en base al ingreso de 
información de marcadores codominantes exigido por GenAlEx v6.4. En el presente estudio se analizaron la diversidad, diferenciación y estructura genética para cada grupo de muestras con los 5 sets de primers microsatélites seleccionados.

La asignación de los individuos a grupos, se la realizó mediante Structure v6.4 (Pritchard et al., 2000), si se toma en cuenta el modelo de "admixture" junto con frecuencias correlacionadas como lo sugieren Falush et al., 2007 en casos de una sutil estructura poblacional. Se determinaron valores de burning lenght de 10000 y un largo de cadena de 100000 con un valor de $\alpha=0.0607$. Luego se definió al valor $\mathrm{K}$ según la técnica de Evanno et al., 2005, con lo cual se obtuvo una probabilidad de la existencia de tres poblaciones. Con este valor, se calculó $\mathrm{Q}$ (proporción de cada individuo en $\mathrm{k}$ poblaciones) y estos datos se transfirieron a Distruct para su visualización y posterior análisis.

Una vez establecido el número de poblaciones de acuerdo con la estructura genética, se prosiguió con los análisis de diversidad y diferenciación genética. Se calcularon frecuencia de alelos, heterocigosidad esperada y observada (HeHo), coeficiente de endogamia, equilibrio de Hardy-Weinberg, distancia genética de Nei y análisis de agrupamientos. Los valores de Hey Ho se los obtuvo a partir de la inferencia del equilibrio de Hardy-Weinberg mediante el programa ARLEQUIN 3.5 con 1000000 de iteraciones para la cadena de Markov y con 1000 pasos de "dememorization". Una vez analizados los valores de $\mathrm{He} \mathrm{y} \mathrm{Ho,} \mathrm{para}$ cada una de las poblaciones, se realizó la prueba de $X^{2}$ con el objetivo de probar si los genotipos observados son consistentes con los esperados bajo apareamiento al azar con $\alpha=0.05 \%$.

La diferenciación genética se la calculó mediante la comparación de pares de poblaciones, a través de la estadística F de Wrights. Este análisis se lo realizó en Arlequin 3.5, ya que este programa permite evaluar la hipótesis nula mediante los valores p. Para ello se utilizó la función de "Compute Pairwise Differences" mediante la opción de "Compute a distance matrix". Después se realizó el análisis de varianza molecular (AMOVA), para conocer en donde se encuentra la mayor variabilidad. La matriz de distancia genética se la elaboró mediante GenAlEx v6.4 a través de la opción de Codom Genotypic, que proporciona una matriz de distancias genéticas individuo por individuo (NxN) (Peakall y Smouse, 2006). Una vez elaborada la matriz de distancia genética se procedió a calcular la distancia genética de Nei.

Los análisis de agrupamiento se los realizó mediante el programa Mega v5.0 de Tamura et al., 2011. Se especificó el tipo de dato "DataType=distance" y la forma de la matriz triangular de las distancias genéticas "DataFormat=lowerleft". Para determinar si existía o no correlación entre la composición genética y la localización geográfica se aplicó el test de Mantel. Para ello se utilizaron los datos obtenidos del GPS y la matriz de distancia genética de 
Nei elaborada mediante GenAlEx v6.4. RESULTADOS

Las distancias geográficas se las realizó con $\log (1+x)$, esto para poder visualizar mejor la correlación entre ambas matrices. La relación entre ambas matrices para el test de Mantel se la elaboró con XLSTAT 2012, mediante la opción de pruebas de correlación/ asociación.
Mediante análisis en Structure v6.4, se pudo determinar una estructura genética de dos poblaciones. Los resultados indican que tanto las poblaciones de CayambeCoca como las de Mojanda comparten un mismo patrón, mientras que la población de Yanacocha muestra otro (Figura 3).

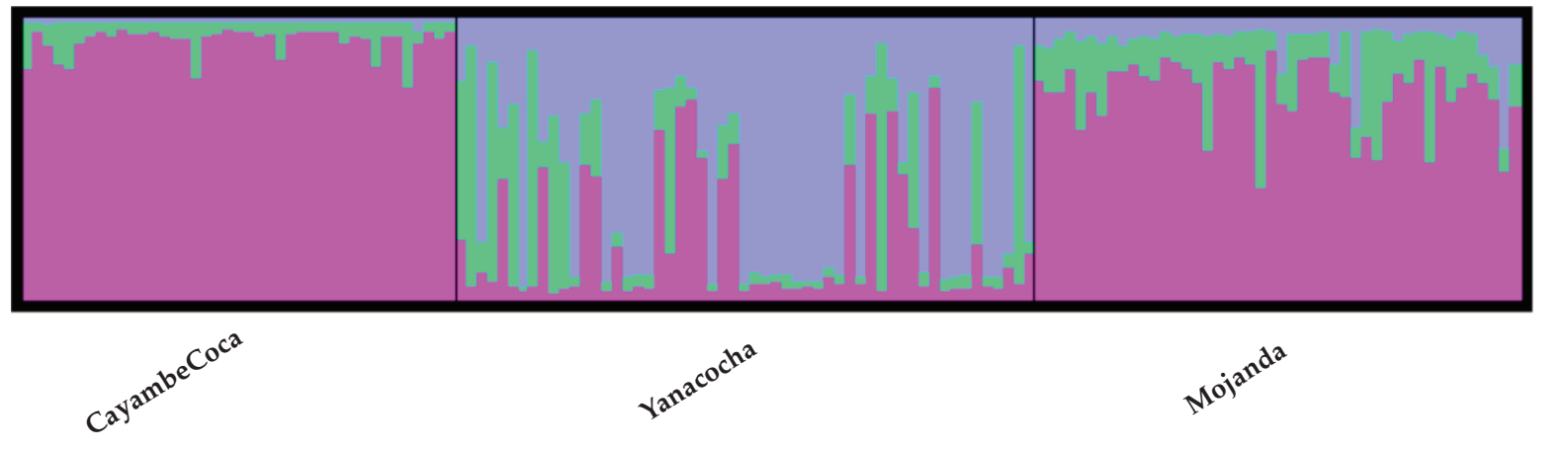

Figura 3. Representación de Q mediante gráfico de barras en Distruct. Cada individuo se representa en una línea vertical, divida en los tres conglomerados definidos. La población Cayambe-Coca es púrpura, Mojanda es verde y Yanacocha es azulado.

En la Figura 4 se muestran los 18 alelos para los 142 individuos con los 5 loci. registrados con sus respectivas frecuencias

Frecuencia de alelos

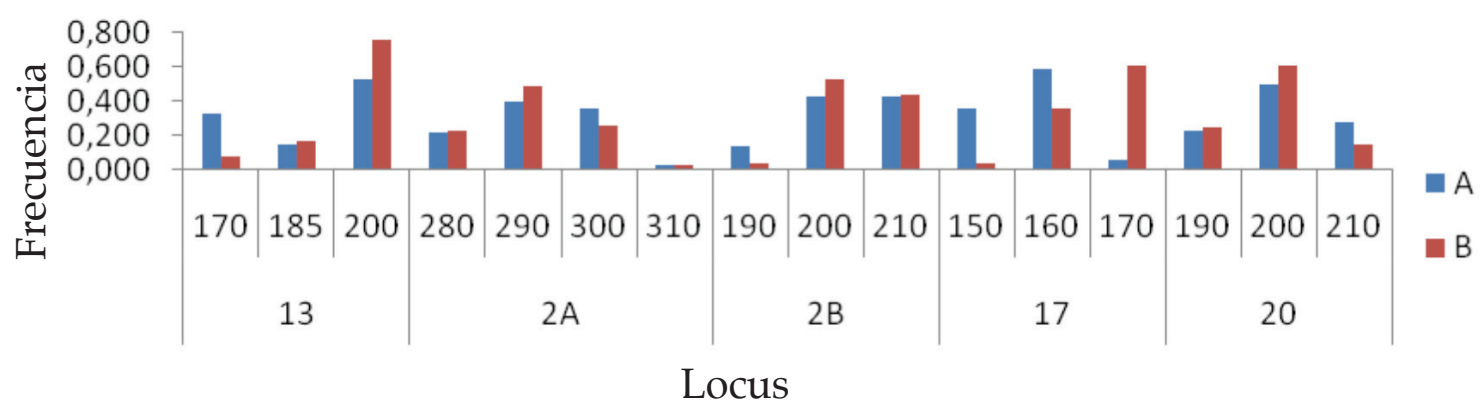

Figura 4. Frecuencia de alelos en los cinco loci para las tres poblaciones. A=Cayambe-Coca y Mojanda, $\mathrm{B}=$ Yanacocha 
Los valores obtenidos de heterocigosidad esperada (He), heterocigosidad observada (Ho) e índices de fijación para las tres poblaciones se resumen en la Tabla 3. Los resultados muestran que la esta población. mayor diferencia entre He y Ho se da en la población de Yanacocha. Igualmente, la mayor diferencia en el índice de fijación es atribuible a Yanacocha, lo cual indica que existe la probabilidad de endogamia en

Tabla 3

Valores de Heterocigosidad observada (Ho), Heterocigosidad esperada (He) e índice de fijación (F) para las dos poblaciones

\begin{tabular}{cccc} 
Población & Ho & He & F \\
\hline $\begin{array}{c}\text { Cayambe-Coca } \\
\text { yMojanda }\end{array}$ & 0.576 & 0.605 & 0.054 \\
Yanacocha & 0.299 & 0.524 & 0.462 \\
\hline
\end{tabular}

El análisis de diferenciación FST en poblaciones son significativamente diferentes los pares de poblaciones a través de valores $\quad(\mathrm{p}=0.00072)$. El análisis de AMOVA mostró p, con 100000 permutaciones y un nivel de que la mayor variación se atribuye a nivel significancia $(\alpha=0,05)$ mostró que las dos individual con casi el $90 \%$ (Tabla 4 ).

\section{Tabla 4}

Análisis de varianza molecular (AMOVA). Considerando 2 poblaciones (Yanacocha y Cayambe CocaMojanda) y 3 subpoblaciones por población

\begin{tabular}{ccccc}
$\begin{array}{c}\text { Fuente de } \\
\text { variación }\end{array}$ & $\begin{array}{c}\text { Grado de } \\
\text { libertad }\end{array}$ & $\begin{array}{c}\text { Suma de } \\
\text { cuadrados }\end{array}$ & Varianza & \% de variación \\
$\begin{array}{c}\text { Entre las } \\
\text { poblaciones } \\
\text { Entre las }\end{array}$ & 1 & 20659 & 0.12678 & 8.16 \\
$\begin{array}{c}\text { subpoblaciones } \\
\text { Individuos en la } \\
\text { subpoblación } \\
\text { Individuos en la } \\
\text { población }\end{array}$ & 133 & 23810 & 0.05864 & 3.77 \\
\hline Total & 142 & 209901 & 0.20987 & 13.51 \\
\hline
\end{tabular}


El dendograma mediante UPGMA otro extremo a Yanacocha. Sin embargo, se (elaborado con el uso de la distancia genética muestra separada la subpoblación Mojanda de Nei), mostró dos grupos principales: 1 (Figura 5).

primero Cayambe-Coca, Mojanda y en

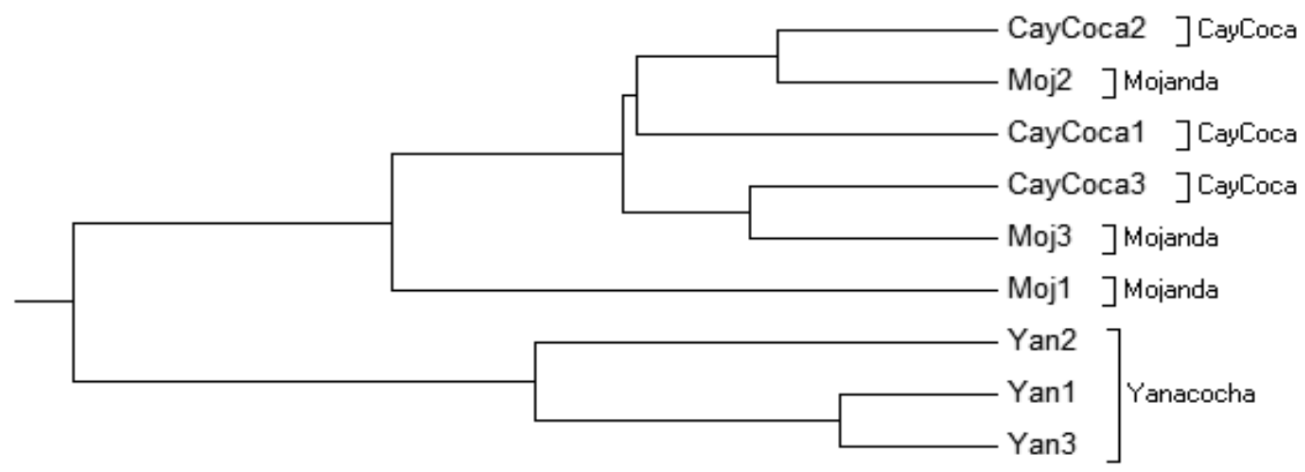

Figura 5. Dendograma derivado de análisis de 5 SSR polimórficos mediante UPGMA, basado en la distancia genética de Nei.

Esta población, debido a indicios de Mantel. El valor calculado en esta prueba es variaciones morfológicas ha sido reportada mayor que el nivel de significancia $\alpha=0.05$ ya como híbrida ( $P$. pauta x $P$. incana) (0.233), por lo tanto no se puede rechazar (Romoleroux, 1996). la hipótesis nula. Es decir, que no existe correlación entre la matriz de distancia

También dentro de los análisis de genética de Nei y la de distancia geográfica, estructura genética se incluyó el Test de donde $\mathrm{R}^{2}=0.0199$ (Figura 6).

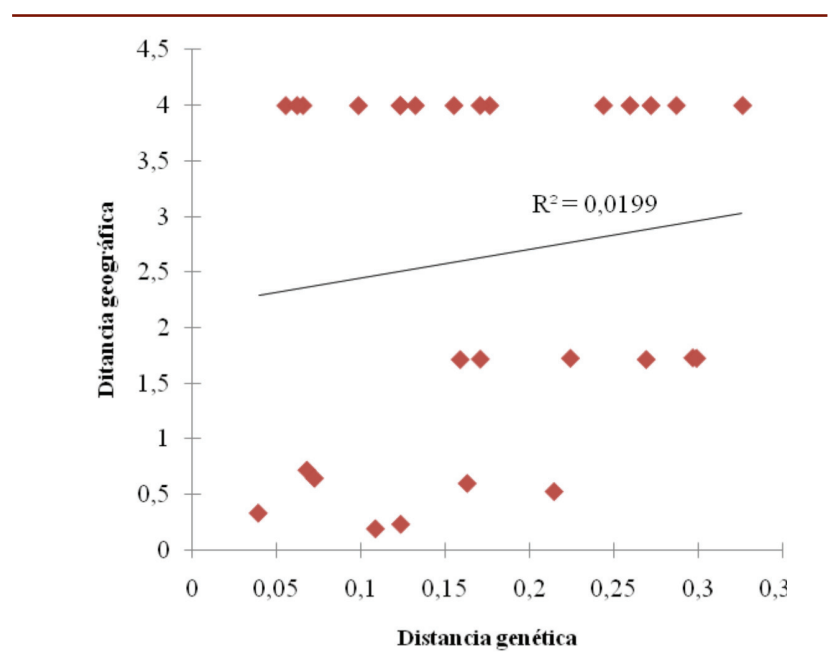

Figura 6. Representación gráfica del test de Mantel, distancia geográfica versus distancia genética de Nei. 


\section{DISCUSIÓN}

Al ser esta una primera investigación en el género Polylepis con microsatélites, los resultados son bastante promisorios. Los resultados indican que Cayambe-Coca y Mojanda (a excepción de Mojanda 1) corresponderían a una población, de acuerdo con estudios previos taxonómicos y revisión de muestras de herbario, pertenecen a la especie P. pauta, mientras que la población de Yanacocha correspondería a otra ( $P$. sericea). Por lo cual el objetivo principal de poder discriminar dos especies morfológicamente ambiguas, se cumplió a cabalidad.

En cuanto a la metodología empleada, en primer lugar, el método de extracción de ADN descrito fue apropiado para la amplificación de secuencias microsatélites. En este género se han reportado varios métodos de extracción de ADN mediante kits comerciales (Julio et al., 2011; SchmidtLebuhn et al., 2006; Kerr, 2004). Además, en el 2011, Hensen et al. reportan un protocolo de extracción en base a CTAB modificado para el estudio de AFLPs. El presente trabajo probó todos estos métodos; sin embargo, dado el número de muestras a tratarse y la cantidad de reactivos a emplear, se optó por utilizar el protocolo de CTAB al $2 \%$ con las modificaciones descritas en materiales y métodos. Este protocolo mostró los mejores resultados tanto en calidad como en costo. Las altas concentraciones de ADN obtenidas mediante este protocolo se atribuyen a varios factores como: alta concentración de antioxidantes (PVP y $\beta$-mercaptoetanol), amplia superficie de contacto entre la muestra y tampón de extracción (mezcla mediante pistilos), precipitación mediante isopropanol y los lavados con etanol, por lo cual se sugiere que en ensayos con muchos individuos ( $\geq 100)$, se use este protocolo ya que es una forma rápida y económica de extraer ADN de alta concentración a partir de material vegetal fresco.

En este género se ha reportado el uso de marcadores del tipo ITS y marcadores cloroplastídicos (Kerr, 2004), AFLPs (Hensen et al., 2011; Schmidt-Lebuhn et al., 2006), RAPD e ISSR (Julio et al., 2008; Ochoa et al., 2008) y marcadores bioquímicos como las aloenzimas (Aragundi et al., 2011). Este es el primer estudio en Polylepis en el cual se utilizan microsatélites para estudios de diversidad genética y estructura poblacional. Al trabajar con un marcador de tipo codominante, se tiene la ventaja de poder usar menos microsatélites; se conoce que para tener inferencias similares, se debe emplear al menos cuatro veces más individuos por locus en un marcador dominante que con un codominante. Es más, cuando las tasas de migración son altas y la heterogeneidad en el genoma es baja, se sugiere incluso el uso de 10 veces más individuos por locus (Lynch y Milligan, 1994). Por lo tanto, el uso de SSRs en Polylepis puede brindar estimados genéticos similares con menor número de secuencias. Los cinco sets de primers aquí utilizados (2F-2Ra, 2F-2Rb, 13F-13R, 17F-17Ra y 20F-20R) fueron seleccionados de acuerdo con el número de productos amplificados, calidad en los perfiles de amplificación, nivel de polimorfismo y reproducibilidad. Sin embargo, es 
importante notar que este es un ensayo piloto. Se logra diferenciar estas dos especies, pero estimaciones genéticas más finas deberán realizarse con un mayor número de muestras y más secuencias microsatélites.

En el presente estudio se detectó que solamente las poblaciones de Yanacocha presentaron una diferencia significativa entre la heterocigosidad observada y esperada. Según el equilibrio de HardyWeinberg, se espera una mayor cantidad de heterocigotos de los observados. Este déficit de heterocigotos se puede explicar por la selección a favor o en contra de un alelo, mediante la endogamia o por la falla de amplificación (Selkoe y Toonen, 2006; Nybom, 2004). En las poblaciones de $P$. sericea de la localidad Yanacocha, se detectó una heterocigosidad observada de 0.3. Este valor es cercano al reportado por Julio et al., $2008(\mathrm{Ho}=0.258)$, en donde explica que este dato es común en plantas con características similares de vida a Polylepis (polinización cruzada, anemófilas y un alto número de cromosomas). En el caso de la heterocigosidad esperada se detectó el valor de 0.576 en la población CayambeCoca, Mojanda. Este valor discrepa con los estudios de Hensen et al. 2011 realizado mediante AFLPs en especies ecuatorianas de $P$. pauta $(\mathrm{He}=0.164-0.273)$.

Estas diferencias se pueden deber al tipo de marcador molecular empleado. En los SSR (codominante) se espera un valor mayor de diversidad ya que los errores en la replicación son más frecuentes que las mutaciones de un solo nucleótido o eventos de inserción o delección, que generan los polimorfismos detectables mediante otros marcadores como los AFLPs (dominantes) (Powell et al., 1996).

La diversidad genética presente dentro y entre las poblaciones surge, de un balance entrela deriva génica, la endogamia, la recombinación, el flujo génico, la mutación y la selección. Este balance es afectado tanto por factores naturales como antropogénicos (Loveless y Hamrick, 1984). En el presente estudio, luego de calcular las heterocigosidades observada y esperada dentro de las poblaciones de Yanacocha $(\mathrm{Ho}=0.3, \mathrm{He}=0.52)$, CayambeCoca, Mojanda $(\mathrm{Ho}=0.58, \mathrm{He}=0.61)$ se determinó que la mayor diferencia en base a $X^{2}$ corresponde a Yanacocha.

Por lo tanto, se puede considerar que las poblaciones de Cayambe-Coca y Mojanda tienen un comportamiento de reproducción al azar, mientras que las poblaciones de Yanacocha no lo tienen. En la presente investigación se observó que la población de Yanacocha se limita un solo bosque continuo. Por el contrario, las poblaciones de Mojanda y Cayambe-Coca tienen una mayor área geográfica, que a pesar de mostrar fragmentación de hábitat, puede darse flujo génico entre sus diversos parches. Por lo tanto, la falta de variabilidad de Yanacocha se puede atribuir a un proceso de endogamia dentro de esta población. Es necesario evaluar en otras regiones del país, la genética de $P$. sericea para plantear acciones de conservación en esta especie. 
Los valores de diferenciación genética reportados en el presente estudio se obtuvieron mediante F'st calculados a partir de AMOVA, prueba con la cual se obtiene una matriz de distancias euclideanas. Esta medida es la más apropiada para determinar la influencia de los procesos demográficos como deriva genética y migración en la estructura genética poblacional (Meirmans y Hedrick, 2011). Sin embargo, es importante considerar que las tasas de migración calculadas mediante Fst, presentan problemas de equilibrio. Esto se debe al modelo usado (isla), que implica supuestos tales como: migración no espacial, tamaños de poblaciones iguales y ausencia de selección. En este trabajo las dos poblaciones descritas (Cayambe-Coca y Mojanda, Yanacocha) son diferentes entre sí. Cayambe-Coca, Mojanda y Yanacocha, se encuentran en lados diferentes de la Coordillera de Los Andes lo cual evitaría el flujo génico a través de polen entre ellas.

La mayor variabilidad detectada se atribuyó a los individuos dentro de cada una de las poblaciones (cerca $90 \%$ ) de toda la variación. Una alta variabilidad en los individuos es consistente con una fragmentación reciente de hábitat que además es común en especies ampliamente dispersas, perennes, con polinización cruzada, anemófilas y un alto número de cromosomas (Hamrick et al., 1979). Por lo cual se podría hipotetizar que la visualización en parches de estos bosques no es su estado natural, sino más bien a efectos de tipo antropogénico. Este porcentaje de variabilidad en los individuos ha sido reportado también por Aragundi et al., (2011) en poblaciones de P. pauta, en estudios de $P$. australis por Hensen et al., (2011) y en estudios mediante AFLPs en $P$. besseri (Gareca et al., 2013).

El análisis de agrupamiento mediante UPGMA, muestra dos poblaciones. Están claramente diferenciadas las poblaciones Cayambe-Coca y Mojanda de Yanacocha. Además, se logra observar que Mojanda 1 (población híbrida) se agrupa en otro conjunto. Los resultados de este análisis permiten considerar a los individuos exclusivos de Yanacocha como $P$. sericea. En cambio, a P. pauta como exclusivo de Cayambe-Coca y Mojanda. Sin embargo, se necesita extender esta investigación a poblaciones más distantes en el Ecuador, para confirmar estos resultados.

En este estudio no se detectó correlación entre distanciagenética y distancia geográfica, lo cual sugiere que las poblaciones de estudio (Cayambe-Coca, Yanacocha y Mojanda) no se conforman con un patrón de aislamiento por distancia. Estos resultados son comunes en el género Polylepis, donde individuos de diferentes poblaciones tienen mayor similitud que los individuos en la misma población (Aragundi et al., 2011; Ochoa et al., 2008). Los resultados en este estudio indican que al menos en las poblaciones estudiadas no existe evidencia de aislamiento por distancia, lo cual se explica por un alto flujo génico entre las poblaciones. En especial, en las poblaciones de Cayambe-Coca y Mojanda. Finalmente, al analizar los resultados de esta investigación se puede concluir que los marcadores 
moleculares SSRs fueron útiles para detectar diversidad, diferenciación y estructura génica en el género Polylepis. Se determinó que las muestras del Parque Nacional CayambeCoca y Mojanda son consistentes con una sola especie: P. pauta. Mientras que las muestras de Yanacocha pertenecen a $P$. sericea. Sin embargo, se necesitan estudios más amplios para poder realizar planes de restauración y conservación en estos bosques.

\section{CONCLUSIONES}

- El método de extracción empleado (CTAB al $2 \%$ modificado) fue óptimo para la extracción de ADN de Polylepis, ya que permitió la obtención de una concentración de ADN superior a $50 \mathrm{ng} / \mu \mathrm{l}$. Es importante mencionar que la extracción debe realizarse en muestra fresca y recién colectada debido a que las muestras tienden a oxidarse fácilmente, por lo cual, mantener la cadena de frío hasta la incubación de las muestras es muy importante.

- Se lograron seleccionar 5 sets de primers para microsatélites a partir de técnicas de PCR tales como TD-PCR y PCR en gradiente, los cuales brindaron gran cantidad de información, buena calidad de datos y disminución de errores de puntuación para los análisis de diversidad, diferenciación y estructura para las poblaciones de Polylepis reportadas. Se sugiere que se incluyan, en futuros estudios, ensayos de secuenciación para poder verificar los resultados obtenidos, así como comprobar la ausencia de efectos homoplásicos.
- Los análisis de diversidad genética muestran que las poblaciones de CayambeCoca y Mojanda tienen un comportamiento de reproducción al azar, así como una poca diferenciación genética. Por el contrario, las poblaciones de Yanacocha no presentaron este tipo de reproducción. Para poder conocer el impacto de la fragmentación y degradación del hábitat en este género, se sugiere comparar las diferentes subpoblaciones dentro de bosques continuos y remanentes de Polylepis con árboles de diferentes edades para poder caracterizar directamente la paternidad, patrones de cruces y eventos de flujo génico.

- Finalmente, los microsatélites SSRs fueron útiles para análisis previos de diversidad, diferenciación y estructura génica en el género Polylepis, ya que se pudo determinar dos grupos altamente diferenciados. El primero conformado por las poblaciones de Cayambe-Coca y Mojanda, donde se considera a la especie $P$. pauta como individuos exclusivos y el segundo por las poblaciones de Yanacocha con $P$. sericea. Se recomienda correlacionar los análisis genéticos aquí reportados con los citogenéticos en las poblaciones analizadas, para afinar los resultados de diversidad obtenidos. También sería adecuado extender el estudio con otras especies dentro del género de Polylepis y otros marcadores codominantes para realizar análisis de filogenia y de filogeografía más completos de este género. 


\section{AGRADECIMIENTOS}

Un agradecimiento a los laboratorios de Biotecnología vegetal y Cultivo de Tejidos de la Carrera de Ingeniería en Biotecnología y a los profesionales colaboradores: Dra. Karina Proaño e Ing. Paola Párraga (Escuela Politécnica del Ejército - Departamento de Ciencias de la Vida). Así mismo un agradecimiento al Ministerio del Ambiente, Dirección Nacional de Pichincha, por el permiso de investigación otorgado para el Parque Nacional Cayambe-Coca ( ${ }^{\circ}$ 048-2011-IC-FLO-DPAP-MA) y a la Fundación Jocotoco por la autorización para colectar muestras en su reserva Yanacocha.

\section{REFERENCIAS BIBLIOGRÁFICAS}

Aragundi S, Hamrick J y Parker K. 2011. Genetic insights into the historical distribution of Polylepis pauta (Rosaceae) in the northeastern Cordillera Oriental of Ecuador. Conservation Genetics, 12: 607-618.

Doyle J J y Doyle J L. 1987. A rapid DNA isolation procedure for small quantities of fresh leaf tissue. Phytochemical Bulletin, 19: 11-15.

Evanno G, Regnaut S y Goudet J. 2005. Detecting the number of clusters of individuals using the software STRUCTURE: a simulation study. Molecular Ecology, 14: 2611-2620.

Falush D, Stephens M y Pritchard J. 2007. Inference of population structure using multilocus genotype data: dominant markers and null alleles. Molecular Ecology Notes, 7: 574-578

Fjeldsa J y Kessler M. 1996. Conserving the biological diversity of Polylepis woodlands of the highland of Peru and Bolivia. A Contribution to Sustainable Natural Resource Management in the Andes. Nordeco. Dinamarca.

Gareca E, Breyne P, Vandepitte K, Chaill J, Fernandez M y Honnay O. 2013. Genetic diversity of Andean Polylepis (Rosaceae) woodlands and inferences regarding their fragmentation history. Botanical Journal of the Linnean Society, 172: 544-554.

Hamrick J, Linhart Y y Mitton J. 1979. Relationships between life history characteristicsandelectrophoretically detectable genetic variation in plants. Annual Review of Ecology, Evolution, and Systematics, 10: 173-200.

Hensen I, Teich I, Hirsch H, Wehrden H y Renison D. 2011. Range-wide genetic structure and diversity of the endemic tree line species Polylepis australis (Rosaceae) in Argentina. American Journal of Botany, 98: 1825-1833.

Julio N, Dueñas J, Reninson D y Hensen I. 2011. Genetic Structure and diversity of Polylepis australis (Rosaceae) tree populations from central Argentina: Implications for forest conservation. Silvae Genetica, 60: 55-56. 
Julio N, Sobral A, Dueñas J, Di Rienzo J Renison D y Hensen I. 2008. RAPD and ISSR markers indicate diminished gene flow due to recent fragmentation of Polylepis australis woodlands in central Argentina. Biochemical Systematics and Ecology, 36: 329-335.

Kerr M. 2004. A phylogenetic and biogeographic analysis of Sanguisorbeae (Rosaceae) with emphasis on the Pleistocene radiation of the high Andean genus Polylepis. Tesis de Doctorado, University of Maryland.

Khanuja S, Shasany A, Darokar M y Kumar S. 1999. Rapid isolation of DNA from dry and fresh simples of plants producing large amounts of secondary metabolites and essential oils. Plant Molecular Biology Reporter, 17: 1-7.

Lynch M y Milligan B. 1994. Analysis of population genetic structure with RAPD markers. Molecular Ecology, 3: 91-99.

Loveless M, y Hamrick J. 1984. Ecological determinants of genetic structure in plant populations. Annual Review of Ecology, Evolution and Systematics, 15: 65-95.

Mecham J. 2001. Causes and consequences of deforestation in Ecuador. Centro de Investigación de los Bosques Tropicales (CIBT). Página de Internet: www.rainforestinfo.org.au/projects/jefferson. htm. Consultada: diciembre-2012.
Meirmans P y Hedrick P. 2011. Assessing population structure: Fst and related measures. Molecular Ecology Resources, 11: 5-18.

Nybom H. 2004. Comparison of different nuclear DNA markers for estimating intraspecific genetic diversity in plants. Molecular Ecology, 13: 1143-1155.

OchoaV,Proaño Ky JiménezP. 2008. Genética poblacional de dos especies de plantas leñosas del páramo ecuatoriano con miras a un proceso de rehabilitación. Tesis de pregrado, Escuela Politécnica del Ejército. Sangolquí, Ecuador.

Peakall R y Smouse P E. 2006. Population genetic software for teaching and research, Molecular Ecology Notes, 6(1): 288-295.

Porebski S, Bailey L y Baum B. 1997. Modification of a CTAB DNA extraction protocol for plants containing high polysaccharides and polyphenol component. Plant Molecular Biology Reporter, 15: 8-15.

Powell W, Morgante M, Andre C, Hanafey M, Vogel J, Tingey S y Rafalski A. 1996. The comparison of RFLP, RAPD, AFLP and SSR (microsatellite) markers for germplasm analysis. Molecular Breeding, 2: 225-238.

Pritchard J, Stephens M y Donnelly P. 2000. Inference of population structure using multilocus genotype 
data. Genetics, 155: 945-959.

Romoleroux K y Pitman N. 2004. IUCN Red List of Threatened Species. Página de Internet: http://www. iucnredlist.org/details/38119/0. Consultada 15-julio-2012.

Romoleroux K. 1996. Rosaceae-Flora of Ecuador. Denmark: Herbario, Departamento de Biología, Pontificia Universidad Católica del Ecuador.

Segovia C, Quijia P, Proaño K, Soltis P y Soltis D. 2010. La Desaparición de los Bosques de Polylepis (Rosaceae: Rosoideae: Sanguisorbeae) en el Ecuador: Hibridización y las implicaciones para su manejo y conservación. Ecociencia. Quito.

Schmidt-Lebuhn A, Kessler M y Kumar M. 2006. Promiscuity in the Andes:
Species Relationships in Polylepis (Rosaceae,Sanguisorbeae) Based on AFLP and Morphology. Systematic Botany, 31: 547-559.

Selkoe K y Toonen R. 2006. Microsatellites for ecologists: a practical guide to using and evaluating microsatellite markers. Ecology Letters, 9: 615-629.

Tamura K, Peterson D, Peterson N, Stecher G, Nei M y Kumar S. 2011. Mega5: Molecular Evolutionary Genetics Analysis using likelihood, distance and parsimony methods. Molecular Biology and Evolution, 28: 2731-2739.

White T, Adams T y Neale D. 2007. Forest Genetics. Primera edición. CAB International. Massachusetts. 682 pp. 